\title{
Olhares sobre a Segunda Guerra Mundial no Brasil
}

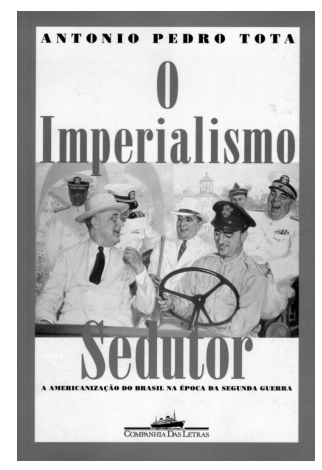

Antônio Pedro Tota O imperialismo sedutor: a americanização do Brasil na época da Segunda Guerra. São Paulo, Companhia das Letras, 2000

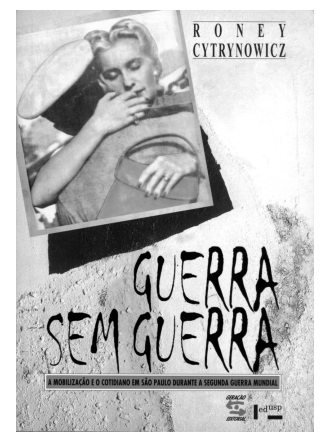

Roney Cytrynowicz Guerra sem guerra: a mobilização e o cotidiano em São Paulo durante a Segunda Guerra Mundial.

São Paulo, Geração Editorial/Edusp, 2000

\author{
A Look on Second \\ World War in Brazil \\ André Luiz Vieira de Campos \\ Universidade Federal Fluminense \\ Rua Hernani Melo 43 - 1301 \\ 24210-130 - Niterói - RJ Brasil \\ camdrepo@cruiser.com.br
}

$\mathrm{O}$

s trabalhos de Roney Cytrynowicz e Antônio Pedro Tota têm em comum o fato de analisarem a história brasileira durante a Segunda Guerra Mundial. Entretanto, suas abordagens e enfoques são bastante diversos, refletindo também preocupações temáticas e conceituais e, naturalmente, escolha de fontes e bibliografia.

O livro de Antônio Tota aborda um tema fascinante e, ao mesmo tempo, pouco estudado pelos historiadores nacionais: a ofensiva cultural realizada pelo governo americano no Brasil, dentro do espírito da 'política da boa vizinhança'. São poucos os trabalhos sobre o tema - a começar pelo já clássico livro de Gerson Moura Tio Sam chega ao Brasil (1984). Este fato torna-se ainda mais evidente quando comparamos a produção nacional com o grande número de trabalhos americanos sobre o tema: basta conferirmos a própria bibliografia utilizada por Tota. O autor, além de trabalhar com uma vasta bibliografia norte-americana sobre seu tema, utilizou fontes textuais, sonoras e iconográficas, tiradas de arquivos norteamericanos e brasileiros. Suas fontes são, principalmente, governamentais, o que naturalmente reflete o recorte de seu objeto: a ação do Office of Coordinatior of Inter-American Affairs (OCIIA) no Brasil, com o objetivo de "seduzir" os brasileiros para uma aliança com os Estados Unidos durante a Segunda Guerra Mundial. Apesar da inexistência de referências explícitas, a linguagem e a estrutura do livro nos fazem acreditar que se trata originalmente de uma tese de doutoramento.

O autor concentra-se no estudo da ação do OCIAA, órgão do governo americano idealizado e dirigido por Nelson Rockefeller, e sua atuação no Brasil no campo da divulgação cultural. Tota limita-se, entretanto, a estudar as divisões de Cinema e de Rádio daquela agência, dando ênfase aos aspectos mais glamourosos desta história, como as viagens culturais de artistas e escritores americanos ao Brasil, além do sucesso de Carmem Miranda e outros artistas brasileiros na terra de Tio Sam, no espírito da 
'boa vizinhança.' Tota enfatiza também os conflitos entre o OCIIA, representado por Rockefeller, e o Departamento de Estado, em torno da disputa de quem orientaria a política cultural norte-americana para a América Latina.

Entretanto, um dado que não é mencionado por Tota é o fato de a atuação do OCIAA não ter se limitado ao campo das relações culturais: sua esfera abrangeu também uma série de outras áreas de interesse, tais como: comércio, finanças, assessoria econômica, transportes, agricultura, administração e saúde pública. Nesse sentido, a americanização de que fala Tota não se limitou aos aspectos culturais enfatizados pelo autor, mas envolveu uma profunda opção por um projeto de desenvolvimento que implicava caminhos menos evidentes e não tão glamourosos quanto os apontados por ele. A americanização do Brasil significou também a americanização de nossa agricultura, sistema de saúde, administração pública, sistemas de transporte, educação etc. Por isso é importante qualificar algumas afirmações do autor, como aquela que anuncia o fechamento do OCIAA em 1946: "A fábrica de ideologias não tinha mais serventia." Ora, é verdade que o OCIAA foi fechado em 1946, porém algumas de suas corporações subsidiárias sobreviveram e continuaram agindo no Brasil pelo menos até 1960. Este foi o caso do Institute of Inter-American Affairs (IIAA), a subsidiária encarregada de lidar com saúde pública nas "outras repúblicas" do hemisfério. O IIAA foi parceiro do brasileiro Serviço Especial de Saúde Pública (SESP) de 1942 até 1960, quando, finalmente, foi extinto já quase às portas do governo Kennedy. A importância do IIAA é enfatizada por vários historiadores americanos que consideram que esta agência, após o fechamento do OCIAA, tornou-se a matriz dos projetos de "assistência" da política externa norte-americana do pós-guerra. O IIAA é apontado como inspirador do Ponto IV, o programa de Truman de 'ajuda' ao Terceiro Mundo, e antecessor da Aliança Para o Progresso, de Kennedy.

Algumas afirmativas apressadas do autor também merecem correção. Entre elas a de que, para Monteiro Lobato, "bastava umas botinas protetoras da saúde nos pés dos jecas e um trator" (p. 11) para americanizar o Brasil. Ora, Lobato, um americanófilo assumido, não era ingênuo. Suas reflexões sobre a industrialização brasileira através do modelo fordista podem ser acompanhadas em livros tais como: América, Ferro, O escândalo do petróleo, O poço do Visconde e Mr. Slang e o Brasil.

Outras afirmativas também merecem observações. Por exemplo, talvez o autor generalize demais a boa vontade dos brasileiros para com os norte-americanos sem a necessária ponderação. A afirmação de que os pilotos americanos que partiram de Washington, em 5 de março de 1941, em direção a diversas capitais latino-americanas "eram recebidos como deuses alados" pelos tabaréus "fascinados pelo blusão de couro e óculos Ray-Ban" (p. 79), tem seu contraponto. Se com certeza houve quem endeusasse os pilotos (The Army and Air Force in World War II, Chicago, University of Chicago Press, 1959, p. 321), aconteceram também reações adversas, como a descrita por John D. Carter: "O primeiro grupo de pilotos americanos que aterrissou em Belém em junho de 1941 foi preso pelas autoridades locais, apesar de o governo brasileiro ter dado permissão para que aviões americanos cruzassem seu território."

Apesar destes detalhes onde o autor, aparentemente, deixa suas fontes "falarem" sem a devida crítica, Tota finaliza seu livro de forma muito mais equilibrada. Sua conclusão é que a "americanização" do Brasil não foi 
simples cópia da cultura americana e, para analisar este processo, mesmo o conceito de "resistência cultural" é insuficiente. Assim, o autor utiliza o conceito de forma mais ampla, aproximando-o da idéia de "antropofagia cultural" de Oswald de Andrade. Para Tota, "um povo só incorpora um determinado valor cultural de outro povo se este fizer sentido no conjunto geral de sua cultura".

Se o livro de Tota aborda um tema pouco explorado na historiografia brasileira, Roney Cytrynowicz teve a feliz inspiração de construir um tema absolutamente ausente, até agora, das análises históricas: o cotidiano dos paulistanos durante a Segunda Guerra Mundial e a memória deixada por este conflito nos habitantes e na geografia da cidade. Depois de constatar que a história da Segunda Guerra Mundial no Brasil resume-se à análise das relações internacionais e ao "jogo duplo" de Vargas, às breves referências da participação da Força Expedicionária Brasileira (FEB) na Itália e aos efeitos da guerra na industrialização do país, Cytrynowicz verifica que a memória da guerra é praticamente ausente no imaginário do paulistano e se pergunta o porquê desta ausência.

A resposta para tal questão está em olhar a mobilização do front interno no Brasil durante a Segunda Guerra Mundial como mais uma estratégia política do Estado Novo visando mobilizar a população para seus ideais. Segundo o autor, "a escassez que atingiu as classes médias e as elites de São Paulo foi mais um álibi para instituir um clima de privação coletiva de forma a tornar a guerra uma experiência coletiva, que deveria unir todos os brasileiros, independentemente de distinções sociais, para organizar a sociedade em moldes estadonovistas. E, igualmente, instituir uma ordem em uma cidade que já se consolidava como metrópole, mas cuja organização e infra-estrutura haviam sido projetadas, a partir da década de 1920, para uma população muito inferior à possuída nos anos 40" (p. 24).

Ainda para os operários e os imigrantes — particularmente os japoneses a guerra significou violenta repressão. $\mathrm{O}$ autor faz uma distinção entre as estratégias do Estado Novo voltadas para as classes médias e aquelas dirigidas aos operários, onde medidas de intervenção direta, militarizadas, atingiram as fábricas em nome da "batalha da produção". Assim, um decreto de julho de 1944 suspendeu vários direitos trabalhistas que haviam sido implantados em 1943 com a CLT. Para os imigrantes italianos, alemães e japoneses, a guerra significou violência e impedimento de falar e manter escolas e jornais em suas línguas maternas. Mas especialmente atingidos foram os japoneses, tornando-se objeto — ao contrário de italianos e alemães — de uma deliberada perseguição racista do Estado Novo, que incluiu deportações, expulsões e confinamentos.

Diante desse quadro, seria de admirar que a memória da Segunda Guerra Mundial em São Paulo fosse cultuada pela população e marcasse a paisagem urbana com monumentos, nomes de ruas e logradouros. Roney compara a memória da revolução de 1932 com a da Segunda Guerra, para concluir que aquela marcou muito mais a memória coletiva e a paisagem urbana de São Paulo do que esta última.

Originalmente uma tese de doutoramento em história social pela Universidade de São Paulo (USP), Guerra sem guerra, além de tratar do cotidiano e da memória da Segunda Guerra em São Paulo, também oferece um panorama geral do Estado Novo. Para isso, o autor utiliza abordagens múltiplas, lança mão de fontes as mais inusitadas e temas os mais diversos. Os capítulos 
do livro compõem um painel através do qual se reconstrói o cotidiano da população de São Paulo durante o conflito. Assim, temas "mais evidentes" numa abordagem sobre a guerra e sua memória são trabalhados, tais como o envio de um grupo de enfermeiras da FEB para a Itália, a "batalha da produção" e a "batalha da borracha", como o governo classificou diferentes aspectos da mobilização econômica para a guerra. Porém, o mais interessante do livro são os "temas inusitados" que o autor construiu, tais como a história do "pão de guerra", a história do gasogênio, do sapato "mobilização", a discussão sobre a "escassez de empregadas" e a mensagem que as letras de samba nos revelam a respeito da visão das camadas populares sobre o Estado Novo e a guerra. A criatividade de Cytrynowicz levou-o a buscar as fontes mais variadas e inusitadas, desde as mais tradicionais fontes textuais até outras menos utilizadas pelos historiadores, como livros de receitas, propaganda em embalagens de pão, diários de pessoas anônimas, letras de música e partituras, além de filmes e fotos. O resultado é um texto atraente e deliberadamente narrativo e com muitas citações de época, segundo o autor "para dar ao leitor um 'sabor' do período".

Tal como um caleidoscópio que produz um número infinito de combinações de imagens, o livro de Cytrynowicz vai construindo quadros e imagens do tempo que retrata, à medida que vamos lendo seus capítulos. Nesse sentido, é importante que se leia o livro inteiro - e não um ou outro capítulo - para que se possa capturar a melhor "imagem possível" do cotidiano da cidade de São Paulo durante a Segunda Guerra Mundial. Ao contrário do livro de Tota, não existe em Guerra sem guerra uma conclusão fechando o livro. São várias histórias, leituras, registros e olhares que o autor vai construindo numa tentativa de abraçar, da forma mais ampla possível, o espectro da diversidade existente numa cidade como a São Paulo da época. O resultado é uma análise histórica séria, mas, ao mesmo tempo, uma leitura agradável e acessível. Com certeza, esta última característica do livro revela o 'outro lado' do historiador: Roney Cytrynowicz é também autor de livros de contos e ganhador de prêmios literários.

Diferentes em suas abordagens e estilos, O imperalismo sedutor e Guerra sem guerra ajudam a compor e iluminar a história do Brasil durante a Segunda Guerra Mundial e merecem ser lidos por todos aqueles interessados em nosso passado recente. 